\title{
Effect of Post -Thaw Addition of Insemination Media and Prostatic Fluid on Dog Sperm Motility Parameters
}

\author{
Violeta IGNA $^{1 *}$, Ramona FENEȘ ${ }^{1}$ and Ileana BRUDIU ${ }^{1}$ \\ ${ }^{1}$ Faculty of Veterinary Medicine, Banat's University of Agricultural Sciences and Veterinary Medicine \\ "King Michael I of Romania" Timisoara, Romania \\ 119 Calea Aradului, 300645 Timisoara, Romania \\ *corresponding author: ignavioleta@gmail.com
}

Bulletin UASVM Veterinary Medicine 75(2)/2018

Print ISSN 1843-5270; Electronic ISSN 1843-5378

doi:10.15835/buasvmcn-vm:2018.0041

\begin{abstract}
:
Improving sperm parameters with a role in fertilization and keeping them as long as possible at optimal levels is still a current requirement for frozen-thawed semen. The aim of the study was to evaluate the effect of the addition of an artificial insemination media (M) and prostatic fluid (PF), post thawing, on dog sperm motility parameters. The sperm rich fraction from nine dog ejaculates was cryopreserved. After thawing, three experimental variants were carried out: 1) semen diluted 1:1 with CaniPlus Enhance-media 2) with the PF and 3) semen without any addition. Samples were incubated at $37^{\circ} \mathrm{C}$ and sperm motility parameters were assessed after $10,25,40$ and 50 minutes. Samples supplemented with the insemination media recorded the highest values of total motility, progressive motility and sperm velocity throughout incubation. Addition of PF had a negative effect on the total and progressive motility values and caused a slight increase in velocity.
\end{abstract}

Keywords: dog, frozen-thawed semen, insemination media, prostatic fluid, sperm motility

\section{Introduction}

Artificial insemination in dog has become a common demand in veterinary clinics. The possibilities of short and long-term preservation of dog spermatozoa generated a gradual development of international exchanges of genetic material in this species. The use of chilled or cryopreserved semen for insemination of the bitch involves a smaller volume of semen and lower quality sperm parameters compared to fresh semen. These are generally compensated by the use of uterine insemination techniques of semen. However, at least one unwanted aspect is associated with each uterine semen deposition techniques: it is difficult to master and cannot be used in all bitches (rigid catheter transcervical insemination); the equipment is not generally available and its expense severely limits its widespread use (endoscopic transcervical insemination and laparascopy); it is invasive and sedation or general anestesia are needed (laparatomy and laparascopy) (Nöthling and Volkmann, 1993). In addition, there are significant ethical and welfare concerns about the use of surgical insemination in bitches (England 2014), especially when non-invasive procedures are available (Thomassen, 2006). In contrast, vaginal insemination is a non-invasive technique, easy to perform, requires simple, cheap, readily available equipment, and does not require sedation or anesthesia of the bitch (Nöthling and Volkmann, 1993, Nöthling, 2007). On the other hand, vaginal insemination is only suitable when large quantities of good quality sperm are available, for example 
when using fresh semen (England, 2014). In this context, vaginal deposition of semen may become the main insemination option, even for preserved semen (chilled or cryopreserved) if optimal solutions are found for some issues. One of them is identifying an insemination fluid to serve in both increasing semen volume and in improving sperm parameters and keeping them at optimal level as long as possible.

The effect of some substances addition to frozen-thawed semen was studied: caffeine, pentoxifylline, 2'-deoxyadenosine (Milani, 2010), albumin-free Tyrode's albumin lactate pyruvate (Nöthling, 2005), autologous prostatic fluid (Nöthling and Volkmann, 1993, Rota 2007, Stanescu Pascal, 2012), homologous prostatic fluid (Nöthling, 2005). Surprising and controversial results were obtained on the addition of prostatic fluid to frozen-twawed semen.

During copulation in dog, the third fraction (prostatic fluid) is ejaculated after the second fraction (sperm rich fraction) of semen. As the seminal fluid is delivered trough the cervix into the uterus, this phenomen tends to force the sperm-rich fraction into the uterus (Senger, 2003). In addition to transport into the uterus of spermatozoa deposited into the vagina, the third fraction has an important effect on regulating fertility and is recomended to be used as a flushing fluid in artificial insemination (England, 2014).

The aim of the study was to evaluate the effect of the addition an artificial insemination media (M) and prostatic fluid (PF), post thawing, on dog sperm motility parameters.

\section{Materials and methods}

Semen collection and evaluation. Five male dogs of different pure breeds (Siberian Husky, American Staffordshire Terrier, English Springer Spaniel, Dogo Argentino and Berna shepherd) aged 2 to 6 years, were used for semen collection. Nine ejaculates were collected by digital manipulation of penis, based on linear cranio-caudal massage of the prepuce, firm movements and compression beyond erectile bulbus, following the procedure described by Christiansen (1984). The second (sperm-rich) fraction and the third (post-sperm rich fraction / prostatic fluid) of the ejaculate were collected using glass containers, prewarmed at $37^{\circ} \mathrm{C}$. Separate collecting of the two ejaculate fractions was attempted.
The evaluation of sperm-rich fraction quality immediately after collecting aimed to assess the following parameters: volume, concentration, total sperm count, total motility, progressive motility, path velocity and sperm morphology.

Concentration, total motility (TM), progressive motility (PM) and path velocity (VAP) were determined by computer-assisted assay with CASA system (IVOS, version 12,3 Hamilton Thorne Bioscience, USA) using Animal motility software and HTB-IVOS seting parameters recommended for dog semen. An aliquot from sperm-rich fraction was diluted with autologous prostatic fraction using the 1:5 dilution rate and gently mixed. A volume of $3 \mu \mathrm{l}$ of the diluted sample was placed on the chamber of Leja slide (Leja Products B. V. Netherlands), and computer-assisted assay was performed.

Morphology was evaluated by examination of stained sperm using the bright field microscopy (Olympus BX51 microscope). Spermatozoa were stained with Spermac (Stain Enterprises, P.O. Box 152, Wellinghton, South Africa), according to the producers' staining procedure. About 200215 sperm per sample were examined at $400 \mathrm{x}$ and 1000x magnification and classified in two categories: normal sperm and abnormal sperm. Immature spermatozoa, having a proximal or distal cytoplasmic droplet in the midpiece, were included in the abnormal sperm category. The percentage of normal spermatozoa was calculated for each semen sample.

Semen cryopreservation. Semen centrifugation was performed only to ejaculates that failed to separate collection of sperm-rich fraction and prostate fractions. The centrifugation parameters were $650 \mathrm{xg}$ (2620 RPM) for 5 minutes.

The sperm-rich fractions were cryopreserved using CaniPlus Freeze (Minitub GmbH, Germany) extender. Semen was extended on a concentration of $100 \times 10^{6}$ spermatozoa $\mathrm{ml}^{-1}\left(50 \times 10^{6}\right.$ spermatozoa / $0.5 \mathrm{ml}$ straw). Straws of $0.5 \mathrm{ml}$ volume were filled with extended semen and sealed with ultrasonic sealer. The semen was equilibrated at $4^{\circ} \mathrm{C}$ for 2 hours and then the straws were placed horizontally at $4 \mathrm{~cm}$ above the surface of liquid nitrogen for $10 \mathrm{~min}$, followed by immersion in liquid nitrogen $\left(-196^{\circ} \mathrm{C}\right)$ and maintaining them in these conditions, in cryogenic container.

Prostatic fluid preservation. Post-sperm rich fraction (prostatic fraction) of each ejaculate was 
Table 1. Mean values \pm SD of sperm-rich fraction parameters, immediately after semen collection $(n=9)$

\begin{tabular}{lcccc}
\hline Parameter & $\begin{array}{c}\text { Volume of } \\
\text { sperm-rich fraction } \\
(\mathrm{ml})\end{array}$ & $\begin{array}{c}\text { Concentration } \\
\left(\text { sperm } \times 10^{6} / \mathrm{ml}\right)\end{array}$ & $\begin{array}{c}\text { Total sperm count } \\
\left(\text { sperm } \times 10^{6}\right)\end{array}$ & $\begin{array}{c}\text { Sperm morphology } \\
(\% \text { normal sperm })\end{array}$ \\
\hline & $3.27 \pm 3.93$ & $253.56 \pm 163.17$ & $493.34 \pm 196.10$ & $77.33 \pm 8.51$ \\
\hline
\end{tabular}

Table 2. Mean values \pm SD of spermatozoa motility parameters evaluated by CASA, before and after the freezing-thawing

\begin{tabular}{cccc}
\hline Semen Treatment & $\begin{array}{c}\text { Total Motility (TM) } \\
(\%)\end{array}$ & $\begin{array}{c}\text { Progresive Motility } \\
(\text { PM }) \\
(\%)\end{array}$ & $\begin{array}{c}\text { Path Velocity } \\
(\text { VAP) } \\
\left(\mu \mathrm{m} \mathrm{s}^{-1}\right)\end{array}$ \\
\hline Fresh semen & $83.67 \pm 11.01$ & $53.89 \pm 17.72$ & $140.77 \pm 14.56$ \\
\hline $\begin{array}{c}\text { Frozen-thawed } \\
\text { semen }\end{array}$ & $51.11 \pm 15.39$ & $14.33 \pm 7.16$ & $89.73 \pm 12.36$ \\
\hline
\end{tabular}

centrifuged at $1500 \mathrm{xg}(3980 \mathrm{RPM})$ for $5 \mathrm{~min}$, to eliminate as many as possible of the spermatozoa from this fraction (Igna, 2007). The supernatant was examined microscopically to check if all the spermatozoa had been removed, then it was filtered and transferred to a plastic vial, labeled with the same code as the corresponding spermrich fraction of the ejaculate, and frozen at $-24{ }^{\circ} \mathrm{C}$ until use.

Post-thaw evaluation. The straws were thawed in a waterbath at $38^{\circ} \mathrm{C}$ for 1 minute. Evaluation of the effect of cryopreservation on sperm motility was done by computer-assisted analysis of the total motility, progressive motility and path velocity.

Post-thaw semen supplementation and spermatozoa motility monitoring. After thawing, $400 \mu \mathrm{l}$ of semen were used for each of the three experimental variants that were carried out: 1) semen supplemented 1:1 with insemination media - CaniPlus Enhance (Minitub GmbH, Germany) (S-IM); 2) semen supplemented 1:1 with the autologous prostatic fluid (S-PF) and 3) semen without any addition (S). Samples were incubated at $37^{\circ} \mathrm{C}$ and sperm motility parameters were assessed after 10, 25, 40 and 50 minutes.

Statistical analysis. Results are expressed as mean \pm SD. Relationships between results were investigated using Mann-Whitney test and KruskalWallis test. We used nonparametric tests because the number of samples was reduced. Results were considered statistically significant when $\mathrm{P}<0.05$ (Brudiu, 2010).

\section{Results and discussions}

The mean values and standard deviation of some parameters (volume, concentration,

total spermatozoa number and morphology) for sperm-rich fraction of ejaculate, immediately after semen collection, are shown in Table 1.

In eight of the nine semen collections, the two fractions of the ejaculate - sperm-rich and post sperm-rich (prostate) fractions, were collected separately, and the sperm-rich fractions volume varied between 1.00 and $4.5 \mathrm{ml}$. Only in one case, separate fractions collection failed, resulting in a $14 \mathrm{ml}$ sperm-rich fraction including a part of prostatic fluid ejaculated.

The concentration values ranged between $30.2-568.6 \times 10^{6} \mathrm{ml}^{-1}$ and those of the total sperm count on the sperm-rich fraction of ejaculate between 193.1 - 884.1 x $10^{6}$ spermatozoa.

Motility parameters from sperm-rich fraction of ejaculate, assesed by computer-assisted semen analysis, before and after the freezing-thawing procedure are reported in Table 2 (Table 2). Cryopreservation caused an important decrease in all sperm motility parameters analysed. The mean value of total motility (TM) after cryopreservation is very close to that reported by de Rota et al. 


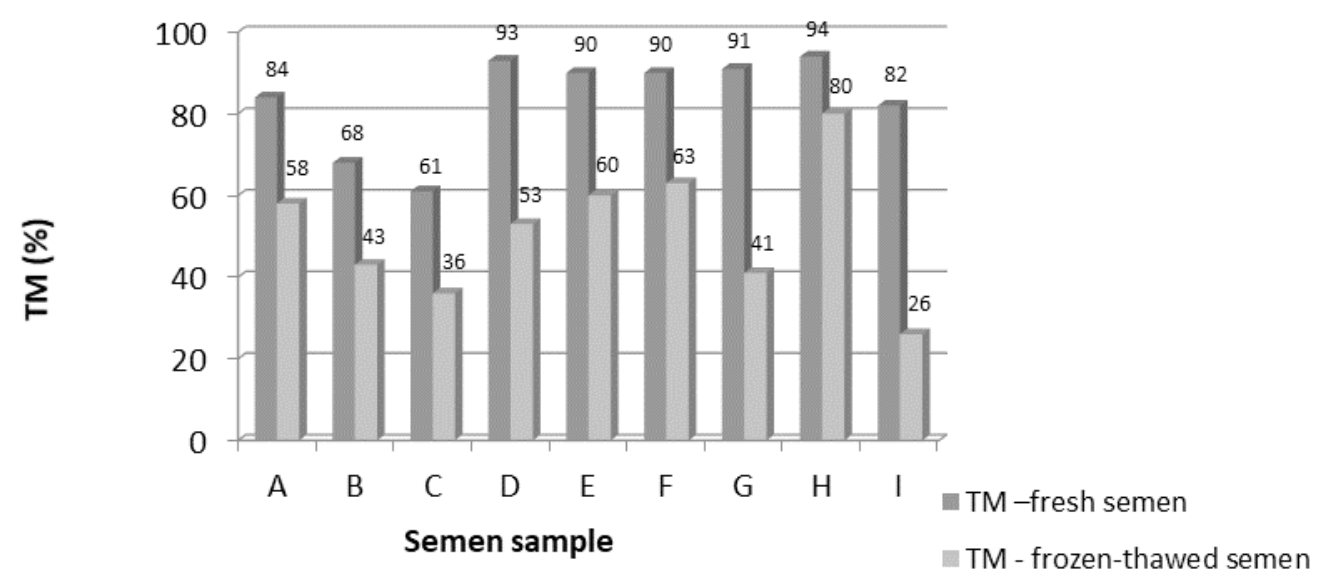

Figure 1. Total motility (TM) values recorded in fresh and frozen-thawed semen $(\mathrm{n}=9)$

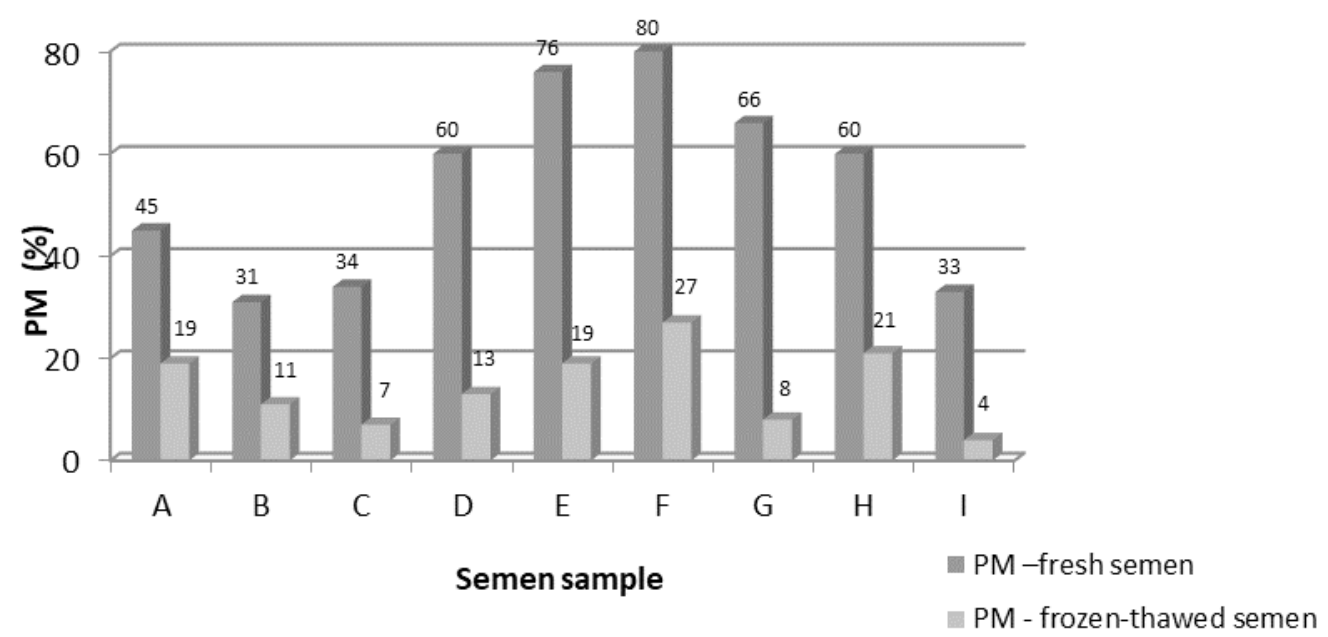

Figure 2. Progressive motility (PM) values recorded in fresh and frozen-thawed semen (n=9)

(2005) $-50.2 \pm 6.0 \%$ as well as that reported by Pop et al. (2006) - 30-50\%, but below the reported values of Silva et al. (2005): $54.6 \pm 11.2$ and $61.3 \pm 9.1 \%$.

The results reveal a heterogeneity of the impact of cryopreservation on total motility (Figure 1) progressive motility (Figure 2 ) and veocity (Figure 3 ), with significant individual differences.

The results recorded during monitoring of spermatozoa motility parameters to frozenthawed semen samples at different incubation times $(10,25,40$ and 55 minutes), of the three experimental variants, are shown in Table 3.

The highest mean values of total motility (TM) were recorded in semen samples without any addition (S) at 10 and 40 minutes of incubation and in semen samples supplemented with insemination media (S-IM) at 25 and 55 minutes of incubation. The lowest total motility values were recorded in semen samples supplemented with autologous prostatic fluid (S-PF) throughout the incubation period. Statistical analysis indicated significant differences for total motility values only between groups S and S-PF at 10 minute of incubation $(\mathrm{P}<0.05)$.

The addition of insemination media has positively influenced the progressive motility of the spermatozoa, the S-IM group having the highest values compared to the $\mathrm{S}$ and S-PF groups. However, no significant differences were found between the three groups (S-IM, S-PF and S) at 10, 25,40 , and 55 minutes of semen incubation.

Post-thaw addition, either of insemination media or prostatic fluid, resulted in a higher velocity than semen without any addition.

The results of various studies, especially those related to the addition of prostatic fluid to frozenthawed semen, are quite difficult to compare due to different experimental conditions. Here are some of the variation elements in the studies on this area: - the origin of the canine spermatozooa used: epididymal spermatozoa (Korochkina et 


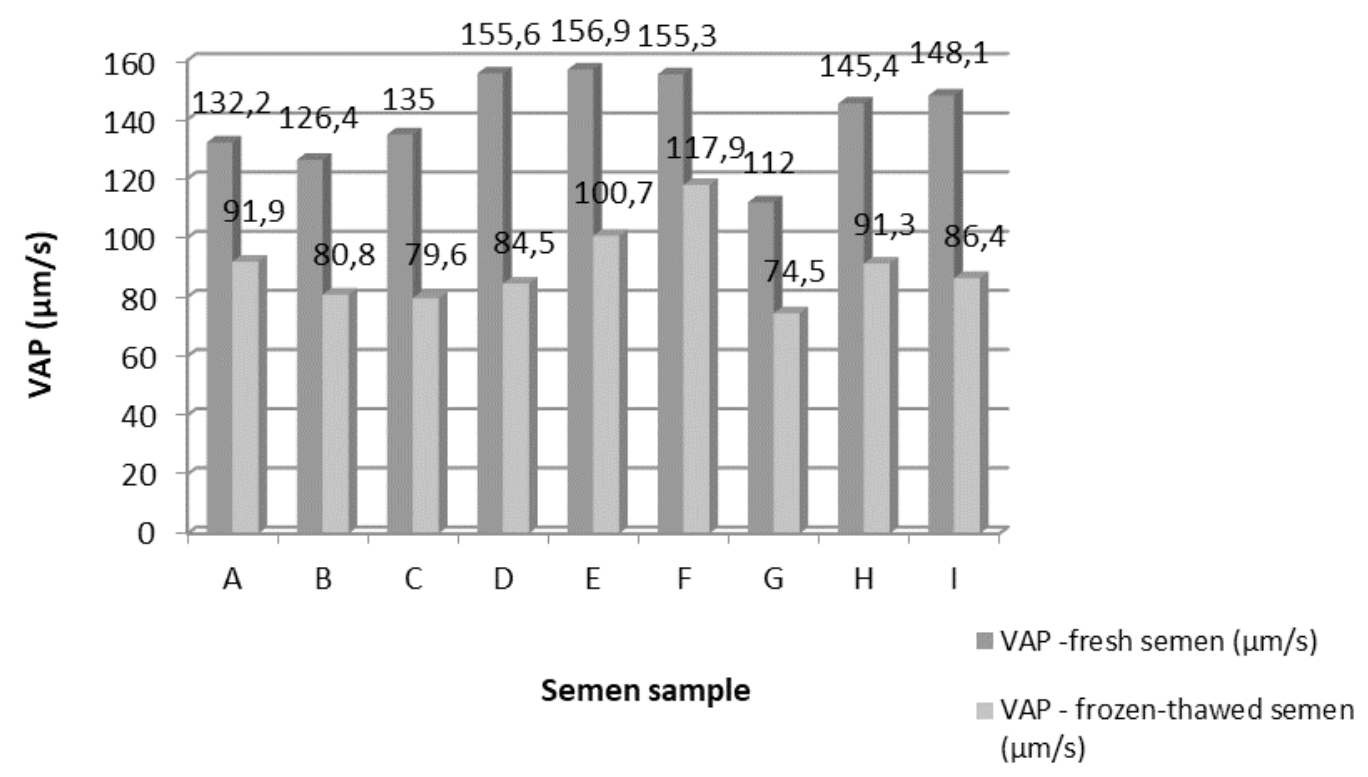

Figure 3. Path velocity (VAP) values recorded in fresh and frozen-thawed semen $(n=9)$

Table. 3. The mean values \pm SD of total motility (TM), progressive motility (PM) and path velocity (VAP) of frozen-thawed semen at different incubation times $(10,25,40$ and 55 minutes), for the three experimental variants: 1) S+IM (semen + insemination media), 2) S-PF (semen sample + prostatic fluid) and 3) S (semen samples - without the addition of any fluid)

\begin{tabular}{cccc}
\hline & $\begin{array}{c}\text { Total Motility (TM) } \\
(\%)\end{array}$ & $\begin{array}{c}\text { Progresive Motility (PM) } \\
(\%)\end{array}$ & $\begin{array}{c}\text { Path Velocity (VAP) } \\
\left(\mu \mathrm{m} \mathrm{s}^{-1}\right)\end{array}$ \\
\hline 10 min & $51.75 \pm 13.40$ & $20.00 \pm 14.82$ & $102.84 \pm 13.27$ \\
\hline S-IM & $38.88 \pm 12.65$ & $11.63 \pm 6.44$ & $93.20 \pm 10.07$ \\
\hline S-PF & $52.88 \pm 13.84$ & $15.25 \pm 9.11$ & $90.61 \pm 7.99$ \\
\hline S & & & $97.79 \pm 13.85$ \\
\hline 25 min & $47.00 \pm 12.31$ & $14.00 \pm 11.24$ & $91.47 \pm 12.47$ \\
\hline S-IM & $33.13 \pm 15.42$ & $8.63 \pm 5.26$ & $84.22 \pm 10.56$ \\
\hline S-PF & $40.38 \pm 12.89$ & $8.38 \pm 6.23$ & $91.86 \pm 10.72$ \\
\hline S & & & $82.63 \pm 11.10$ \\
\hline 40 min & $26.88 \pm 15.51$ & $5.88 \pm 7.00$ & $81.15 \pm 7.60$ \\
\hline S-IM & $20.25 \pm 12.80$ & $2.750 \pm 1.909$ & $84.45 \pm 13.56$ \\
\hline S-PF & $28.63 \pm 12.58$ & $3.75 \pm 3.92$ & $72.2 \pm 31.1$ \\
\hline S & & & $78.85 \pm 8.54$ \\
\hline 50 min & $18.25 \pm 15.14$ & $3.50 \pm 5.53$ &
\end{tabular}

al., 2014), spermatozoa from sperm-rich fraction collected separately (Nöthling et Volkmann, 1993, Nöthling et al., 2005) and spermatozoa from the complete ejaculate collected (Rota et al., 2007); - the origin of prostatic fluid : prostatic fluid collected from the same donor dog used in the study, usually collected separately during the same ejaculation (autologous PF) (Nöthling et Volkmann, 1993, Stănescu et al., 2012) or the whole ejaculate collected and then separated the prostatic fluid by centrifugation (Rota et al., 2007); prostatic fluid collected from a dog other than the sperm donor used in the study (homologous PF) (Nöthling et al., 2005, Korochkina et al., 2014) or 
prostatic fluid colected from diferent dogs (others than sperm donors) and mixed together (mixture of homologous PF) (Milani et al., 2010); - prostatic fluid processing regime, especially centrifugation parameters' values (g force or revolutions per minute and centrifugation time) which differ almost in each study: one step of $3000 \mathrm{rev} \mathrm{min}^{-1}$ for 5 min (Nöthling et Volkmann, 1993), $300 \mathrm{~g}$ for 5 min (Milani et al., 2010); $1000 \mathrm{x}$ g for $10 \mathrm{~min}$ (Nöthling et al., 2005), 1118 x g 10 min (Stănescu et al., 2012), or two step centrifugation when the prostatic fluid was separated from the complete ejaculate: $700 \mathrm{~g}$ for $6 \mathrm{~min}$ then a second time $1200 \mathrm{~g}$ for $6 \mathrm{~min}$. (Rota et al., 2007), 700x g for 6 minutes, the supernatant removed and centrifuged again at $3468 \mathrm{x}$ g for 10 minutes (Korochkina et al., 2014); - the dilution rate of frozen-thawed semen with prostatic fluid: 1:1 (Korochkina et al., 2014), 1:2 (Rota et al., 2007, Stănescu et al., 2012), 1:3 (Nöthling et al., 2005); - incubation condition: in vivo (artificial insemination of the bitch) (Nöthling et Volkmann, 1993, Nöthling et al., 2005) or in vitro at $37^{\circ} \mathrm{C}$ (Milani et al., 2010, Korochkina et al., 2014) or 38ㄷ (Rota et al., 2007).

Some older (Bartlet, 1962, Mann, 1954) and more recent studies (Mogielnicka-Brzozowska et al., 2014, Mogielnicka-Brzozowska et al., 2015, Souza et al., 2007) aim to identify the composition of seminal plasma, the origin of its components, and its relation to spermatozoa and process of fertilization. Continuing research on this area is necessary to identify the nature and composition of an addition fluid in artificial insemination with frozen-thawed semen, for improving fertility.

\section{Conclusion}

This study reveals the beneficial effect of the added insemination media, post-thawing, on motility parameters of dog spermatozoa. Addition of prostatic fluid had a negative effect on the total motility and progressive motility values during incubation and caused a slight increase in spermatozoa velocity.

\section{Acknowledgments.}

This study was realised using the infrastructure project "Dezvoltarea infrastructurii de cercetare, educaţie şi servicii în domeniile medicinei veterinare şi tehnologiilor inovative pentru RO 05", cod SMIS-CSNR 2669.

\section{References}

1. Bartlett DJ (1962). Studies on dog semen. II. Biochemical characteristics. Journal of Reproduction and Fertility, 3:190-205.

2. Christiansen IbJ (1984). Reproduction in the Dog and Cat. Eastbourne: Bailliere Tindall, (Chapter 4).

3. Brudiu I (2010). Biostatistica in apordarea practică. Timisoara: Eurobit.

4. England GCW, Russo M, Freeman SL (2014). Artificial insemination in dog. In Practice, 36:77-84.

5. Esch M (2014). Performance of CaniPlus Freeze Extender for freezing canine semen, Technical Report, www. minitube.de. Accessed 10.07.18.

6. Igna V and Pană R (2007). The influence of different centrifugation regime on dog spermatozoa. Bulletin USAMV-CN, 64(1-2): 448-453.

7. Korochkina E, Johannisson A, Goodla L, Morrell JM, Axner E (2014). Effect of prostatic fluid on the quality of fresh and frozenthawed canine epididymal spermatozoa. Theriogenology, 82: 1206-1211.

8. Mann T (1954). The biochemistry of semen. Methuen, London.

9. Milani C, Fontbonne A, Sellem E, Stelletta C, Ge'rard O, Romagnoli S (2010). Effect of post-thaw dilution with caffeine, pentoxifylline, 2'-deoxyadenosine and prostatic fluid on motility of frozen-thawed dog semen. Theriogenology 74: 153-164.

10. Mogielnicka-Brzozowska M, Strzezek R, Wasilewska K and Kordan W (2015). Prostasomes of Canine Seminal Plasma - Zinc-Binding Ability and Effects on Motility Characteristics and Plasma Membrane Integrity of Spermatozoa. Reprod Dom Anim, (50): 484-491.

11. Mogielnicka-Brzozowska M, Dziekońska A, Strzeżek R, Załęcki M, Majewska A, Tołścik K, Kordan W (2014). Effect of seminal plasma zinc-binding proteins on motility and membrane integrity of canine spermatozoa stored at $5^{\circ} \mathrm{C}$. Bull Vet Inst Pulawy, 58: 163-168

12. Nöthling JO and Volkmann DH (1993). Effect of addition of autologous prostatic fluid on the fertility of frozenthawed dog semen after intravaginal insemination. J Reprod Fertil Suppl 47: 329-333.

13. Nöthling J0, Shuttleworth R, de Haas K, Thompson PN (2005). Homologous prostatic fluid added to frozen-thawed dog spermatozoa prior to intravaginal insemination of bitches resulted in better fertility than albumin-free TALP. Theriogenology 64, 975-991.

14. Nothling JO, Gerber D, Colenbrander B, Dijkstra M, Bakker T, De Cramer K (2007). The effect of homologous prostatic fluid on motility and morphology of dog epididymal spermatozoa extended and frozen in Biladyl with Equex STM paste or Andromed. Theriogenology 67: 4-275.

15. Pascal Stanescu M, Van den Berghe F, Aissi A, Birtoiu AI, Deleuze S (2012). The Effect Of Homologous Prostatic Fluid On The Parameters Of Dog Semen Extended And Frozen In TriseggYolk And INRA Freeze: Preliminary Results. Reproduction in Domestic Animals, 47 (Supp 14): 431-432. 
16. Pop AR, Groza I, Bartos A, Breg A (2006). Research on dog's semen cryopreservation. Buletin USAMV-CN, 63:374-378.

17. Rota A, Rota A, Martini M., Milani, C, Romagnoli S (2005) Evaluation of dog semen quqlity after slow (biological freezer) or rapid (nitrogen vapours) freezing, Reprod. Nutr. Dev., 45 (1): 29-37.

18. Rota A, Milani C, Romagnoli S (2007). Effect of post-thaw dilution with autologous prostatic fluid on dog semen motility and sperm acrosome status. Theriogenolog,y 67: 520-525.

19. Senger PL (2003). Pathways to Pregnancy and Parturition (Second Revised Edition) Washington: Current Conceptions, Inc.

20. Silva AR, Cardoso RCS, Silva LDM (2005). Comparison between different dilution rates on canine semen freezing using Tris - buffer with the addition of egg-yolk and glycerol. Arq. Bras. Med. Vet. Zootec., 57 (6), 764 -771.

21. Souza FF, Barreto CS, Lopes MD (2007). Characteristics of seminal plasma proteins and their correlation with canine semen analysis. Theriogenology, 68:100-106.

22. Stănescu (Pascal) M, Birtoiu I, Deleuze S (2012). Influence of autologous prostatic fluid added to frozen-thawed dog semen. Scientific Works - University of Agronomical Sciences and Veterinary Medicine, Bucharest Series C, Veterinary Medicine, 58 (4): 350-358.

23. Thomassen R, Sanson G, Krogenaes A, Fougner JA, Berg KA, Farstad W (2006). Artificial insemination with frozen semen in dogs: a retrospective study of 10 years using a non-surgical approach.Theriogenology, 66:1645-50. 